\title{
Cardiovascular Drugs Inducing QT Prolongation: Facts and Evidence
}

\author{
Carlos A. Taira ${ }^{*}$ Javier A. W. Opezzo, Marcos A. Mayer and Christian Höcht
}

Cátedra de Farmacología e Instituto de Fisiopatología y Bioquímica Clínica (INFIBIOC), Facultad de Farmacia y Bioquímica, Universidad de Buenos Aires, Argentina

\begin{abstract}
Acquired QT syndrome is mainly caused by the administration of drugs that prolong ventricular repolarization. On the other hand, the risk of drug-induced torsades de pointes is increased by numerous predisposing factors, such as genetic predisposition, female sex, hypokalemia and cardiac dysfunction. This adverse reaction is induced by different chemical compounds used for the treatment of a variety of pathologies, including arrhythmias. As it is known, antiarrhythmic agents and other cardiovascular drugs can prolong the QT interval, causing this adverse reaction. Of the 20 most commonly reported drugs, 10 were cardiovascular agents and these appeared in 348 of the reports (46\%). Class Ia antiarrhythmic agents have frequently been linked to inducing arrhythmia, including torsades de pointes. Sotalol and amiodarone, class III antiarrhythmics, are known to prolong the QT interval by blocking $\mathrm{I}_{\mathrm{Kr}}$. Due to the severity of events caused by the therapeutic use of these drugs, in this work of revision the cardiovascular drugs that present this property and the factors and evidence will be mentioned.
\end{abstract}

Keywords: QT interval, drug-induced torsades de pointes, antiarrhythmic drugs, amiodarone, sotalol, HERG channel.

\section{INTRODUCTION}

The prolongation of the QT interval of the electrocardiogram has either a congenital origin due to mutations in ion channels or an acquired origin, generally due to the administration of QT-prolonging drugs [1]. The prolongation of this segment is related to the appearance of early post-potentials and the increase of the dispersion of the QT period in the different layers of the myocardium [1]. These electrophysiological abnormalities give rise to TdP, also called polymorphic ventricular tachycardia, which usually causes syncope, ventricular fibrillation and sudden death [2]. This adverse reaction is induced by different chemical compounds used for the treatment of a variety of pathologies, including arrhythmias. As it is known, antiarrhythmic agents and other cardiovascular drugs can prolong the QT interval, causing this adverse reaction. Due to the severity of events caused by the therapeutic use of these drugs, in this work of revision the cardiovascular drugs that present this property and the factors and evidence will be mentioned.

\section{DRUGS THAT MAY CAUSE QT PROLONGATION OR TORSADES DE POINTES}

In his review, Darpö [3] wrote that, in all, 225 pharmaceutical compounds have been associated with torsades de pointes (TdP) in spontaneous adverse reaction reports collected by the WHO Drug Monitoring Centre. Of the 20 most commonly reported drugs, 10 were cardiovascular agents and these appeared in 348 of the reports $(46 \%)$.

On the other hand, several drugs have been withdrawn from the U.S. market or have received black box warnings due to their potential to cause QT interval prolongation that

*Address correspondence to this author at the Cátedra de Farmacología, Facultad de Farmacia y Bioquímica, Universidad de Buenos Aires, Junín 956, (C1113AAD), Buenos Aires, Argentina; E-mail: ctaira@ffyb.uba.ar leads to fatal ventricular arrhythmias and sudden cardiac death $[4,5]$. Table 1 lists some cardiovascular drugs capable of prolonging the QT interval.

Table 1. Antiarrhythmic and Cardiovascular Drugs that Induce QT Prolongation

\begin{tabular}{|c|c|}
\hline Generic Name & Risk \\
\hline \multicolumn{2}{|l|}{ Antiarrhythmics } \\
\hline Amiodarone & A \\
\hline Disopyramide & A \\
\hline Dofetilide & A \\
\hline Flecainide & B \\
\hline Ibutilide & A \\
\hline Procainamide & A \\
\hline Quinidine & A \\
\hline Sotalol & A \\
\hline \multicolumn{2}{|l|}{ Cardiovasculars } \\
\hline Bepridil & A \\
\hline Dobutamine & B \\
\hline Dopamine & B \\
\hline Adrenaline & B \\
\hline Indapamide & B \\
\hline Isradipine & B \\
\hline Moexipril & B \\
\hline Nicardipine & $\mathrm{B}$ \\
\hline
\end{tabular}


The ability of a drug to prolong the QT period is related to the interference of inward and outward ionic currents in ventricular action potential [6]. Most of the drugs that exhibit this property increase the duration of the action potential by reducing the delayed rectifier potassium current, due to a blockade of the current's rapid component $\left(\mathrm{I}_{\mathrm{Kr}}\right)$ [7].

In the ventricles, loss of function mutations in the genes which encode $\mathrm{K}^{+}$channels and drugs (mainly HERG channel antagonists) are related to hereditary and acquired long QT syndrome, respectively, that put individuals at high risk for developing TdP arrhythmias and life-threatening ventricular fibrillation [8]. Similarly, $\mathrm{K}^{+}$channel down-regulation in heart failure also increases the risk of sudden death [8].

On the other hand, the prolongation of the QT period of the electrocardiogram is used as a marker of a drug's ability to induce TdP [4]. Nevertheless, the relation between the prolongation of the QT interval and the incidence of this arrhythmia is imperfect. Drugs like amiodarone and verapamil, which prolong the interval significantly, show a low incidence of polymorphic ventricular tachycardia [9]. This is explained because these drugs present other actions, such as the blockade of L-type calcium channels which diminish the capacity to cause early post-potentials [10]. This suggests that it is important to consider not only a drug's ability to prolong the QT interval, but also possible pharmacological properties that diminish the alterations of the increase of action potential duration. It is currently generally accepted that the dispersion of the QT interval caused by a drug may be a more reliable parameter of the potentiality of a drug to cause TdP, since a greater dispersion of the QT interval facilitates the maintenance of this arrhythmia by a re-entry mechanism [11]. The incidence of TdP due to clinical drug use prolonging the QT interval is not well known [12]. The data of incidence of this adverse reaction are obtained mainly from spontaneous reports of adverse events. According to an epidemiological study carried out in Sweden, the incidence of TdP is estimated to be 10 times greater than the incidence reported [13]. In the case of antiarrhythmic drugs, like quinidine, the incidence of this adverse reaction is higher than $1 \%$ [5]. The incidence of this proarrhythmia due to class III antiarrhythmic drugs varies from drug to drug. Sotalol and dofetilide present a 3\% risk, whereas amiodarone and azimilide present an extremely lower incidence [14]. This smaller incidence may be related to the ability of amiodarone and azimilide to block the rectifier current, Ikr as well as Iks [14].

Because the information on drug-associated $\mathrm{TdP}$ is constantly growing in line with the increasing awareness and concern, we kindly ask the reader to use the Internet for updates. The www.torsades.org website provides updated information about QT-prolonging agents.

\section{FACTORS FOR DRUG-INDUCED QT PROLONGAT- ION AND TORSADES DE POINTES}

Table $2[5,15]$ shows some risk factors for induction of long QT intervals and TdP. Factors include genetic predisposition, gender, drug use, drug interactions and cardiac abnormalities.

\section{Genetic Predisposition}

It is widely known that congenital long QT syndrome is related to the existence of mutations in ion channels that take part in the processes of depolarization and repolarization of
Table 2. Some Risk Factors for Drug-Induced Torsades de Pointes [5,15]

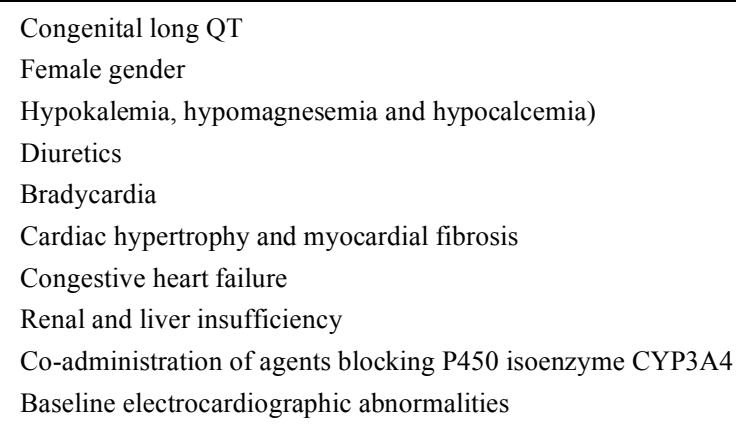

myocardial cells, which is also a factor in drug-induced TdP $[8,16]$. On the other hand, although these mutations are rare ( 1 in 500 patients) [16], the existence of patients with ion channel mutations that present subclinical long QT syndrome has been established in recent years $[17,18]$. Although these patients present a normal or slightly increased QT interval, they are more likely to exhibit QT interval prolongation from exposure to drugs, since they would present a reduced repolarization reserve [19]. Therefore, whereas the administration of QT-prolonging drugs would have minimum effects in normal patients, in patients with silent ion channel mutations, the administration of these drugs would cause an exaggerated prolongation of this interval and a greater risk of proarrhythmia [19]. A possible explanation may be the presence of a subclinical mutation of the intervening ion channel in the slow component of the delayed rectifier current $\left(\mathrm{I}_{\mathrm{Ks}}\right)$. This mutation would not be significant in normal conditions due to the predominant role of $\mathrm{I}_{\mathrm{Kr}}$ in repolarization, but it would be substantial if it was blocked. The presence of silent mutations was identified in $15 \%$ of patients with acquired long QT syndrome [20, 21]. On the other hand, genetic alterations also affect the plasma elimination of drugs, giving rise to greater plasma drug levels and a greater risk of TdP. It is known that the increase of plasma levels of most QTprolonging drugs is dose-dependent, thus causing a greater prolongation of ventricular repolarization [22]. Two metabolic enzymes that present genetic polymorphism are CYP2D6 and CYP2C cytochrome P450 isoforms [22, 23]. Thus, there are people with fast metabolism with an enzyme with normal metabolic capacity, and people with slow metabolism with an aberrant enzyme. In Caucasians, the population with slow metabolism represents between $5 \%$ and $10 \%$ of total population. Several QT-prolonging drugs are metabolized by the CYP2D6 and CYP2C enzymes. These patients, when presenting deficient purifying capacity, will present high plasma levels and a greater risk of dosedependent adverse reactions. Another protein involved in pharmacokinetic processes is P-glycoprotein, which takes part in the body's drug extrusion in the gastrointestinal tract and the kidneys [24]. A fraction of the P-glycoprotein population expresses one anomalous transporter, presenting a smaller capacity of extrusion and therefore increased plasma levels of those drugs that are substrates for this glycoprotein, such as amiodarone, digoxin and quinidine [25]. 


\section{Physiological and Pathological Factors}

The QT interval of the electrocardiogram and its druginduced prolongation can be increased by physiological and pathological factors. It is widely known that women present a longer QT interval than men, besides exhibiting a greater susceptibility to drug-induced prolongation [14]. Two thirds of the cases of TdP induced by reported drugs were observed in women [14]. On the other hand, anorexia nervosa, which affects $1 \%$ of young women, causing sudden death in a significant percentage of patients, appears to be related to an additional prolongation of the QT interval, which could be explained by electrolyte disorders as well as by unknown factors [26]. Bradycardia also favors the prolongation of the QT interval, which suggests that the effect drug-induced prolongation will be marked in patients with bradycardia or atrioventricular conduction problems [27]. Since the length of the interval is dependent on the heart rate, the interval should be corrected [28]. Other widely-known factors are electrolyte disorders. Hypokalemia and hypomagnesemia favor a greater prolongation by drugs $[5,15,29,30]$. Renal and hepatic perfusion is reduced in patients with cardiac dysfunction, favoring smaller systemic drug elimination [14].

Myocardial alterations induced by acute myocardial infarction and left ventricular hypertrophy also favor a greater prolongation of the QT interval, as well as a greater dispersion between the different layers of myocardial cells [31]. On the other hand, heart failure causes an exaggerated prolongation of repolarization in canine Purkinje fibers [32].

Various forms of cardiac disease and rhythm disturbances result in altered ion channel and transporter function. These alterations appear in many instances to be part of the homeostatic adaptive response to the primary dysfunction, but then results in secondary cardiac dysfunction, including tachyarrhythmias. So, heart disease modifies the operation of ion channels and transporters in a way that induces the occurrence of rhythm disturbances through the arrhythmogenic remodeling process [33].

$\mathrm{K}^{+}$currents play an important role in shaping the cardiac action potential, and remodeling-induced changes in $\mathrm{K}^{+}$ currents are important contributors to repolarization abnormalities associated with heart failure. Some of the changes in heart failure mimic congenital channelopathies that produce long QT syndromes, and congestive heart failure can be viewed like an acquired QT prolongation [33, 34]. Down-regulation of transcript expression plays a role in the changes in $\mathrm{K}^{+}$current function associated with heart failure. Posttranscriptional and posttranslational mechanisms may be important in heart failure-related $\mathrm{I}_{\mathrm{Ks}}$ downregulation, a fact that would not be surprising in view of the regulation of $\mathrm{I}_{\mathrm{Ks}}$ function by associated proteins in macromolecular complexes $[33,35]$. The down-regulation of $\mathrm{K}^{+}$currents can promote arrhythmogenic early afterdepolarizations, either by prolonging action potential duration in the voltage range at which $\mathrm{I}_{\mathrm{CaL}}$ reactivation generates afterdepolarizations or by reducing the repolarization reserve [36-38].

On the other hand, cardiac failure has effects on cellular $\mathrm{Ca}^{2+}$ handling. Triggered activity related to delayed afterdepolarizations caused by spontaneous diastolic $\mathrm{Ca}^{2+}$ release is a mechanism underlying ventricular arrhythmias induced by cardiac failure $[33,39,40]$. Delayed afterdepolarizations occur in congestive cardiac failure despite reduced $\mathrm{Ca}^{2+}$ stores because of some features of heart failure-induced ion transport remodeling [33, 40-42]: I) hyperphosphorylated $\mathrm{Ca}^{2+}$ release channels are prone to spontaneous diastolic $\mathrm{Ca}^{2+}$ release, II) for any given level of $\mathrm{Ca}^{2+}$ release, enhanced $\mathrm{Na}^{+}-\mathrm{Ca}^{2+}$ exchange function increases the depolarizing current resulting from electrogenic $\mathrm{Ca}^{2+}$ extrusion, and III) $\mathrm{I}_{\mathrm{K} 1}$ down-regulation increases membrane resistance, resulting in a larger depolarization for a given inward current.

In the ventricle, electrical remodeling has been related to changes in T-wave morphology [43]. Moreover, ventricular remodeling is associated with prolongation of repolarization [44-46]. Rapid ventricular pacing for shorts periods $(1 \mathrm{~h})$ can cause changes in ventricular repolarization and changes in activation sequence over 3 weeks was associated with reduced expression of $\mathrm{I}_{\mathrm{to}}$ and $\mathrm{I}_{\mathrm{to}}$ channel mRNA [44-46]. On the other hand, the electronic load imposed by a change in activation sequence reduces the upstroke amplitude, which, in turn, attenuates $\mathrm{I}_{\mathrm{to}}$ triggering down-regulation of the ionic current [47].

\section{DRUG INTERACTIONS}

The simultaneous use of drugs that induce prolongation of the QT interval is another risk factor for TdP. This risk factor can be avoided by the correct prescription of drugs. Drug-induced prolongation of the QT interval can be increased by the joint administration of another drug with the same pharmacodynamic property, or drugs that inhibit the systemic elimination of drugs that reduce plasma potassium levels [12]. On the other hand, agents with sympathomimetic activity also promote drug-induced TdP, since they increase calcium influx through L-type channels [10]. Numerous reports have shown a risk of proarrhythmia increased by association of two drugs that prolong ventricular repolarization [12]. Considering the high rate of prescription of these drugs, and that they are used for the treatment of different pathologies, it would not be strange for a patient to be prescribed two drugs with the same property. Viskin et al. [12] reviewed the reports of 229 cases of drug-induced TdP, finding that in $39 \%$ there had been joint administration of two QT-prolonging drugs. It is also worth noting that this drug interaction is easily avoidable by knowing the pharmacodynamic properties of interacting drugs. Listings of QT-prolonging drugs are available on websites such as www.torsades.org, which is regularly updated. Consulting these bibliographical sources could help avoid this type of potentially fatal drug interaction. In addition, if a patient who is under treatment with a QT-prolonging drug requires the administration of a drug of another pharmacological class, the physician should select the drug within the class with the smaller potential for prolonging ventricular repolarization. A great amount of QT-prolonging drugs is eliminated through hepatic metabolism by various cytochrome P450 isoforms. So, it has been demonstrated that the administration of erythromycin (a CYP3A4 inhibitor) significantly increases the levels of quinidine (a substrate of the CYP3A4 enzyme), increasing the risk of TdP $[48,49]$. 
We also need to consider that several drugs, including thiazide diuretics and $\beta$ agonists, cause hypokalemia and therefore exacerbate the drug-induced prolongation of the QT interval [50]. For example, the diuretic indapamide induces hypokalemia and blocks the slow component of the delayed rectifier $\mathrm{K}^{+}$current $\left(\mathrm{I}_{\mathrm{Ks}}\right)$ and potentiates the effects of sotalol, leading to excessive lengthening of cardiac repolarization and to the development of $\operatorname{TdP}[51,52]$.

\section{ANTIARRHYTHMIC AND CARDIOVASCULAR DRUGS THAT MORE COMMONLY CAUSE TORSADES}

\section{Antiarrhythmic Drugs}

Class Ia antiarrhythmic agents have frequently been linked to inducing arrhythmia, including TdP, by blockade of $\mathrm{K}^{+}$current, similarly to class III agents $[3,53,54]$. Sotalol and amiodarone, class III antiarrhythmics, are known to prolong the QT interval by blocking the $\mathrm{I}_{\mathrm{Kr}}$. However, the risk of TdP with amiodarone is low when compared with sotalol [3, 53, 54]. Higher drug concentrations of sotalol can lead to QTc intervals that are prolonged by approximately 10 to 40 milliseconds, thereby increasing the incidence of TdP. With the exception of quinidine, the degree of QT prolongation linked to the antiarrhythmics depends on the serum drug level [55].

On the other hand, the class III agents blocking the IKr and the human channel is encoded by the human ether-a-gogo-related gene (HERG) $[8,56]$. The inhibition of HERG $\mathrm{K}^{+}$ currents causes lengthening of the cardiac action potential and may produce beneficial class III antiarrhythmic effect. In contrast, an excessive reduction of these currents due to either genetic defects or adverse drug reactions can lead to hereditary or acquired long QT syndrome and an increased risk for TdP and sudden death $[8,56]$.

\section{Class I Antiarrhythmic drugs}

Disopyramide is a well-known antiarrhythmic agent with several indications for the treatment of arrhythmias [57]. Some precautions are electrocardiogram, monitoring and dose adjustment to prevent QT prolongation, and the correction of hypokalemia before initiating therapy $[57,58]$.

Disopyramide inhibits HERG-encoded potassium channels at clinically relevant concentrations and this action may constitute the molecular basis for acquired LQTS associated with this drug [59].

The class I antiarrhythmic agent procainamide is used for the treatment of ventricular tachycardia, premature ventricular contractions, paroxysmal atrial tachycardia, etc., and it is known to induce prolongation of the QT interval $[10,57]$. Ellebongen et al. [60] recommend that patients being started on antiarrhythmic therapy with procainamide be admitted to the hospital for monitoring to ensure that their QT interval is not excessively prolonged.

Foo and $\mathrm{Nq}$ [61] reported the case of a 43-year-old Chinese woman who complained of a one week history of irregular rapid palpitations associated with chest discomfort and dyspnea, and a wide complex tachycardia with a slightly irregular rhythm. Delta waves were also present. When she was treated with intravenous procainamide, she developed TdP secondary to prolonged QT interval.
In their review about quinidine, Grace and Camm [62] wrote that syncope and sudden death have been recognized as potential complications of quinidine therapy and both are usually due to polymorphic ventricular tachycardia. The use of quinidine, one of the earliest antiarrhythmic drugs developed, fell dramatically in favor of newer antiarrhythmic medications when increased risk of ventricular arrhythmia and death with quinidine emerged [62, 63]. However, at this time there is a renewed interest in the use of quinidine. In particular, quinidine appears to be safe and efficacious in combination with verapamil for the treatment of atrial fibrillation. Quinidine has also been used successfully to treat idiopathic ventricular fibrillation, Brugada syndrome, and short QT syndrome [63].

TdP by quinidine also occurs during long-term treatment, usually in association with an identifiable trigger. It may occur in patients with a structurally normal heart but is more likely to occur in those with heart-muscle disease, in patients given quinidine combined with digoxin, or those with hypokalemia or hypomagnesemia [62]. It has been demonstrated that an inhibitor of the CYP3A4 significantly increases the levels of quinidine, increasing the risk of TdP $[48,49]$.

Quinidine-associated TdP is more common in women than in men, as is TdP associated with other antiarrhythmic drugs, possibly because of estrogen-dependent delayed repolarization [62]. It was estimated that quinidine can cause TdP in $1 \%$ to $8 \%$ of patients, even at lower doses [3]. The degree of QT prolongation linked to quinidine does not depend on the serum drug level $[55,62]$.

Flecainide is a class Ic antiarrhythmic agent that can block the delayed rectifier potassium current [64]. This agent is used as a provocative test to unmask the electrocardiogram (ECG) phenotype of the Brugada syndrome, as well as longterm treatment for long QT-3 syndrome, since it also shortens the QT interval [65]. Mutations of the cardiac sodium channel gene, SCN5A, are present in both long QT and Brugada syndromes [66]. Recently, Bernart et al. [67] reported a case where oral flecainide induced syncope with a Brugada ECG pattern in a patient with known long QT-3 syndrome.

\section{Class III Antiarrhythmic Drugs}

In their report, Letsas et al. [68] investigated the causative medications and underlying risk factors that predisposed to drug-induced QT interval prolongation in twenty-one patients with drug-induced long QT $(90 \%$ females, mean age $64.3 \pm 14.1$ years). They reported that known cardiac agents (mainly class III antiarrhythmics) were implicated in 13/21 (62\%), antipsychotics in 8/21 (38\%), and antibiotics in $5 / 21$ patients $(24 \%)$. These authors observed a significant correlation between administration of cardiac agents and TdP events $(\mathrm{P}<0.05)$.

Most of these class III agents, e.g. dofetilide, d-sotalol and sematilide, are powerful $\mathrm{I}_{\mathrm{Kr}}$ blockers, but other mechanisms may also contribute to the antiarrhythmic effects (as may be the case with, for example, ibutilide and azimilide) [56]. Moreover, $\mathrm{I}_{\mathrm{Kr}}$ is encoded by the HERG related gene and class III antiarrhythmic agents inhibit the HERG currents [56]. With amiodarone, the incidence of TdP is very low [69]. In several clinical trials, no proarrhythmia 
occurred during treatment with intravenous amiodarone for conversion of atrial arrhythmias to sinus rhythm [70-72]. With $\mathrm{d}, 1$-sotalol, the incidence of TdP is about $2 \%$ [73-76]. With dofetilide, ibutilide and almokalant, the incidence varies between $1 \%$ and $8 \%$ [3].

Dofetilide is a highly specific class III methanesulfonanilide antiarrhythmic drug. This drug selectively blocks the rapid component of the cardiac ion channel delayed rectifier current and it works by selectively blocking the rapid component of the delayed rectifier outward potassium current, $\mathrm{I}_{\mathrm{Kr}}$ [56]. The drug appears to primarily block activated channels and has a much lower affinity for closed and inactivated channels [77]. At nanomolar concentrations, this agent prolongs both the atrial and ventricular effective refractory periods and AP duration. Dofetilide does not appear to interact with other cardiac ion channels, and this explains its minimal effects upon conduction velocity, myocardial contractility and systemic hemodynamics. Dofetilide prolongs the QT interval with little effect on QT dispersion. No effect was observed on conduction parameters PA, AH, M HV, PR or QRS intervals, sinus cycle length or sinus node recovery [56].

In the Symptomatic Atrial Fibrillation Investigation Research on Dofetilide (SAFIRE-D) trial, the drug was evaluated for its ability to convert and maintain SR in patients with chronic atrial fibrillation (AF) $(85 \%$ of patients) or atrial flutter. After the first 105 patients were enrolled, the dosing protocol was altered to adjust for baseline renal function (creatinine clearance) and change in QTc interval duration. There were two cases of nonfatal TdP considered a result of dofetilide therapy; both occurred within the first 3 days of therapy [56]. Prolongation of QTc duration accounted for 10 withdrawals, and one SD occurred. Dosage adjustment based on creatinine clearance or QTc prolongation was required in $33 \%$ of patients. As a result of this trial, starting therapy in the hospital and adjusting dosage based on creatinine clearance and QTc prolongation are required to minimize the risk of proarrhythmia [56].

Like other class III drugs, the prolonged QT interval occurring in the patients treated with dofetilide can be complicated by TdP. The incidence of $\mathrm{TdP}$ is dosedependent, and is $0.3-10.5 \%$. The risk appears to be dosedependent, with an increased incidence of TdP associated with higher doses of dofetilide administered. The risk of inducing $\mathrm{TdP}$ can be decreased by taking precautions when initiating therapy, such as hospitalizing individuals for a minimum of three days for serial creatinine measurement, continuous telemetry monitoring and availability of cardiac resuscitation. Severity of heart failure $(\mathrm{HF})$, female gender, and QTc duration make it possible to identify patients with a high risk of early TdP when treated with dofetilide. Patients with recent myocardial infarction (MI) had TdP less often compared with patients with chronic HF [78].

Ibutilide is a selective class III antiarrhythmic agent that when administered intravenously can terminate AF and atrial flutter. It is an antiarrhythmic medication that helps return the heart to its normal sinus rhythm [56, 57]. Ibutilide reduces abnormal electrical signals that cause AF by stabilizing the heart muscle tissue. Ibutilide is given intravenously. It acts for only a short period. The drug is used for the cardioversion of atrial flutter and AF, but it can cause TdP [56, 57].

Ibutilide may cause many side effects. It should be used carefully, and patients should be closely monitored for a minimum of $4 \mathrm{~h}$ in the hospital after receiving ibutilide. Cardiac side effects of ibutilide include rapid, uncontrolled heart rhythm: ventricular tachycardia (VT), nonsustained monomorphic VT, TdP or ventricular fibrillation (VF) [56, 57].

Higher drug concentrations of sotalol can lead to QTc intervals that are prolonged by approximately 10 to 40 milliseconds, thereby increasing the incidence of TdP [55]. The incidence of sotalol-induced $\mathrm{TdP}$ is $0.3 \%$ for a daily dose of $80 \mathrm{mg}, \sim 1 \%$ for patients taking between 160 and 240 $\mathrm{mg} /$ day, and up to $5-7 \%$ for a daily dose of $480-640 \mathrm{mg}$ [54]. The risk is much higher in women and those with renal or congestive heart failure, sustained ventricular tachycardia, and with concomitant use of diuretics and hypokalemia [54].

Recently, the review study by Aström-Lilja et al. [79] of the Swedish pharmacovigilance database reported that, among a total of 61,788 adverse reactions recorded between 1991 and 2006, 88 cases of TdP were identified. In these cases, 27 different suspected drugs were implicated. Cardiac drugs were involved in most reports $(74 \%$; 65/88), with sotalol being the most frequently suspected drug $(57 \%$, 58/88).

In a case report of cardiac side effects of sotalol, Srivastava et al. [80] reported that a 44 year-old woman anesthetized for a transplant nephrectomy, had several runs of ventricular tachycardia followed by ventricular fibrillation requiring $30 \mathrm{~s}$ of cardiopulmonary resuscitation, after which she reverted to sinus rhythm. Subsequent investigation found that she had toxic serum levels of sotalol, with a prolonged corrected QT interval on the electrocardiogram. She was started on sotalol while her renal graft was functioning well but it was not reviewed when the graft started to fail and she had to commence hemodialysis. This led to the accumulation of sotalol and explains her serum sotalol value of $7.1 \mathrm{mg} / \mathrm{l} \mathrm{on}$ the day of the event and concentrations greater than $2.5 \mathrm{mg} / 1$ are generally considered toxic.

Yalta et al. [81] reported a case with a severely prolonged QT interval and TdP after an initial intake of low dose sotalol $(80 \mathrm{mg})$, indicating a probable inherent individual oversensitivity to sotalol. Letsas et al. [82], regarding this last report, suggested that pharmacologic challenge with sotalol may successfully identify patients with normal QTc intervals and reduced repolarization reserve that are at increased risk to develop drug-induced long QT syndrome and TdP.

A curious case of suicide attempt was reported by Cherpanatath et al. [83]. These authors reported that a $62-$ year-old man was brought into the intensive care unit because of a cardiac arrest. After extensive resuscitation, including defibrillation, sinus bradycardia occurred with marked QT prolongation, followed by recurrent episodes of TdP. The hetero-anamnestic data revealed a suicide attempt with sotalol.

Although amiodarone is approved by the US Food and Drug Administration (FDA) only for refractory ventricular 
arrhythmias, it is one of the most frequently prescribed antiarrhythmic medications in the United States. Amiodarone is among the most effective with the additional advantage of having little proarrhythmic potential [56]. The favorable efficacy profile of amiodarone during electrical remodeling, particularly the marked increase in amiodarone on atrial refractory periods prolongation in early electrical remodeling, may explain its superior clinical efficacy over existing antiarrhythmic drugs [84].

Amiodarone has a low incidence of cardiac adverse events. With amiodarone, the incidence of TdP is very low $[3,54]$. In seven clinical trials, with a total of 882 patients, no proarrhythmia occurred during treatment with intravenous amiodarone for conversion of atrial arrhythmias to sinus rhythm [3].

In elderly women long-term amiodarone treatment could result of combined block of the rapid and slow delayed outward potassium current components, translated to the ECG in a (more than expected) prolonged QT interval, an augmented transmural dispersion of repolarization (TDR) and an interrupted T-wave [56]. The unequal regression of repolarization lengthening made it possible to individualize $\mathrm{I}_{\mathrm{K}}$ current components in the inscription of the interrupted Twave, which argues against the U-wave as a separate entity. Silent ion channel gene mutations or polymorphisms and down-regulation of beta-adrenergic activation of $\mathrm{I}_{\mathrm{Ks}}$ may underlie the unusual repolarization behavior. The unequal regression over time of amiodarone induced repolarization lengthening could have clinical significance [56, 85].

\section{CALCIUM ANTAGONISTS}

Bepridil is a calcium antagonist which in some countries is labeled for use only in patients who are refractory to other antianginal drugs. Although it is no longer sold in the United States, it has been discussed as a possible option for the treatment of atrial fibrillation [86].

Bepridil is a multi-channel blocker acting to block calcium, potassium and sodium channels, and has characteristics similar to those of class III antiarrhythmic drugs. Reports have shown that bepridil also affects pharmacological cardioversion in a manner similar to that of class III antiarrhythmic drugs. Bepridil's success rate is, at most, 34-58\%; hence, the conversion effect of bepridil alone is not always satisfactory [87-89].

Bepridil prolongs the QT interval and several cases of TdP have been described. In particular, sinus bradycardia and a prolonged QT interval are known proarrhythmic effects of bepridil, and the administration of bepridil at high doses is associated with the development of TdP [90, 91]. Yasuda et al. [91] have reported that $\mathrm{TdP}$ appeared in approximately $1 \%$ of patients with atrial flutter or fibrillation who received bepridil. They described torsades de pointes as manifesting with hypokalemia, particularly in elderly female patients.

\section{DIURETICS}

Diuretic-induced hypokalemia is believed to be the common underlying mechanism of $\mathrm{TdP}$ under certain circumstances. Indapamide-induced syncope has been described in a patient with long QT syndrome, and has been attributed to electrolyte disturbances (hypokalemia) [92].

Indapamide also displays direct effects on ionic currents. This diuretic blocks the slow component of the delayed rectifier $\mathrm{K}^{+}$current $\left(\mathrm{I}_{\mathrm{Ks}}\right)$ and potentiates the effects of dl-sotalol on ventricular repolarization, leading to excessive lengthening of cardiac repolarization and predisposing to the development of TdP [51, 52]. Indapamide has been shown to inhibit the $\mathrm{Na}^{+}\left(\mathrm{I}_{\mathrm{Na}}\right)$, ultrarapid delayed rectifier $\mathrm{K}^{+}$and transient outward $\mathrm{K}^{+}$currents in atrial myocytes [93].

Letsas et al. [94] described a drug interaction with indapamide. It was a case of acquired long QT and TdP ventricular tachycardia in a woman with systemic lupus erythematosus and hypertension receiving prednisolone and indapamide.

\section{MISCELLANEOUS}

Ambasilide is a class III antiarrhythmic which has been shown to block multiple cardiac channels including betaadrenergic antagonism. Although the electrophysiological effects of ambasilide are characterized on the cellular level, its effects on an organ level have yet to be investigated. Ambasilide prolonged the RR, PQ, QRS, QT, and QTc in a concentration-dependent manner in either normal SR or with reduced heart rate (atriotomy). $\mathrm{dP} / \mathrm{dtmin}$ was increased (became less negative) in the presence of increasing concentrations of ambasilide, whereas the vehicle produced less negative lusitropy.

Ambasilide demonstrated use dependence by prolonging QTc less at slower heart rates [56, 95].

Sematilide, a close structural analog of Nacetylprocainamide, is a class III agent which acts largely by delaying conduction. The electrophysiological profile of sematilide is consistent with the selective block of outward potassium currents and associated isolated lengthening of the ventricular effective refractory period and AP duration [56].

Sematilide exerts class III actions in patients: it prolongs QTc in a dose- and concentration-related fashion, does not alter PR or QRS, and slows heart rate at high concentrations. The relations between dose and total area under the timeconcentration curve, dose and peak plasma concentration, and peak plasma concentration and increase in QTc were linear. QTc increases of approximately equal to $25 \%$ were seen at plasma concentrations of approximately equal to 2.0 $\mathrm{mg} / \mathrm{mL}$. The mean elimination half-life was $3.6 \pm 0.8 \mathrm{~h}$, and most of a dose $(77 \pm 13 \%)$ was recovered unchanged in the urine $[56,96]$.

Plasma concentrations greater than or equal to 0.8 $\mathrm{mg} / \mathrm{mL}$ suppressed arrhythmias (5 patients) or aggravated them (3 patients), including 1 patient who needed cardioversion for an episode of TdP $(2.7 \mathrm{mg} / \mathrm{mL})[56,97]$.

Mibefradil, a $\mathrm{T}$ channel blocker, was withdrawn after only one year on the market, largely due to numerous drugto-drug interactions, since it inhibited both CYP3A4 and 2D6 isoenzymes [98]. Mibefradil also gave rise to QT prolongation and marked T-wave morphological changes that resembled those seen with selective class III antiarrhythmics, and this caused a considerable debate as to whether the drug had proarrhythmic potentials. There were 
several reports of TdP in patients on mibefradil during its short time on the market, but it is not fully clear whether it was a proarrhythmic propensity of the drug or pharmacokinetic interactions with other drugs that prolonged the QT interval. In either case, it is noteworthy that the combination of mibefradil and class I and III antiarrhythmics was particularly harmful in a large trial on 2,590 patients with congestive heart failure [99].

Miyajima et al. [100] examined the effect of the angiotensin II receptor blocker valsartan on QT dispersion and the relationship between oxidative stress and QT dispersion in patients with essential hypertension. These authors concluded that antihypertensive therapy with valsartan reduces QTc dispersion and this may be related to the ability of valsartan to reduce oxidative stress in patients with essential hypertension.

Recently Abraham et al. [101] reported that exposure to catecholamines and beta-receptor agonists used routinely during procedures and diagnostic tests can precipitate all the features of stress cardiomyopathy, including cardiac isoenzyme elevation, QTc interval prolongation, and rapidly reversible cardiac dysfunction.

On the other hand, in a recent case report, Quan et al. [102] informed that, strikingly, QTc prolongation was induced along with syncope after dobutamine infusion in a patient with a mutation of the KNCQ1-gene encoding serine instead of glycine.

Aliskiren, not yet approved by the FDA for the treatment of hypertension, manages hypertension by direct renin inhibition [57]. The side effect profile for aliskiren has not yet been fully described. Recently Peitz et al. [103] described the first apparent report of aliskiren-induced QT prolongation resulting in $\mathrm{TdP}$.

\section{THERAPY: $\beta$-BLOCKER EFFICACY IN THE TREATMENT OF LONG QT SYNDROME}

$\beta$-blocker efficacy in long QT syndrome type 1 is good but variably reported, and the causes of cardiac events despite beta-blocker therapy have not been ascertained. Recently Vincent et al. (2009) [104] carried out a retrospective study of the details surrounding cardiac events in 216 genotyped long QT syndrome type 1 patients treated with $\beta$-blocker and followed up for a median time of 10 years. Twelve patients (5.5\%) suffered cardiac arrest (CA)/sudden death, but 11 of $12(92 \%)$ were noncompliant $(n=8)$, were on a QT-prolonging drug $(n=2)$, or both $(n=1)$ at the time of the event. The risk for CA/sudden death in compliant patients not taking QT-prolonging drugs was dramatically less compared with noncompliant patients on QT-prolonging drugs (odds ratio, 0.03; 95\% confidence interval, 0.003 to $0.22 ; \mathrm{P}=0.001$ ). None of the 26 patients with CA before beta-blocker had CA/sudden death on betablockers. These authors state that $\beta$-blockers are extremely effective in long QT syndrome type 1 and should be administered at diagnosis and ideally before the preteen years. Moreover, $\beta$-blocker noncompliance and use of QTprolonging drug could be responsible for almost all lifethreatening "beta-blocker failures" [104].

On the other hand, the aim of a study by Erdil et al. [105] was to evaluate whether esmolol has an effect on QT interval during induction of anesthesia using etomidate and fentanyl in patients with known coronary artery disease. Sixty patients were prospectively randomized to either a control group or the esmolol group. In the esmolol group, QTc interval was significantly shorter compared to the control group $(\mathrm{p}<0.05)$. The authors conclude that infusion of esmolol attenuated the QTc interval prolongation associated with tracheal intubation.

\section{REFERENCES}

[1] Gorda RM, Khan IA, Wilbur SL, Vasavada BC, Sacchi TJ. Torsade de pointes: the clinical considerations. Int J Cardiol 2004; 96:1-6.

[2] Shah RR. Drug-induced prolongation of the QT interval: why regulatory concern? Fundam Clin Pharmacol 2002; 16:119-24.

[3] Darpö B. Spectrum of drugs prolonging QT interval and the incidence of torsades de pointes. Eur Heart J Suppl 2001; 3 (suppl K): K70-K80.

[4] Al-Khatib SM, Allen LaPionte N, Kramer JM, Califf RM. What clinicians should know about the QT interval. JAMA 2003; 289 : 2120-7.

[5] Roden DM. Drug-induced prolongation of the QT interval. N Engl J Med 2004; 350:1013-22.

[6] De Ponti F, Poluzzi E, Cavalli A, Recanatini M, Montanaro N. Safety of non-antiarrhythmic drugs that prolong the QT interval or induce torsade de pointes. Drug Safety 2002; 25:263-86.

[7] Tamargo J, Caballero R, Gómez R, Valenzuela C, Delpón E. Pharmacology of cardiac potassium channels. Cardiovasc Res 2004; 62: 9-33.

[8] Ravens U, Cerbai E. Role of potassium currents in cardiac arrhythmias. Europace 2008; 10: 1133-7.

[9] Van Opstal JM, Schoenmakers M, Verduyn SC, et al. Chronic amiodarone evokes no torsade de pointes arrhythmias despite QT lengthening in an animal model of acquired long-QT syndrome. Circulation 2001; 104: 2722-7.

[10] Cubeddu LX. Qt prolongation and fatal arrhythmias: a review of clinical implications and effects of drugs. Am J Ther 2003; 10: 452-7.

[11] Belardinelli L, Antzelevitch C, Vos MA. Assessing predictors of drug-induced torsade de pointes. Trends Pharmacol Sci 2003; 24: 619-25.

[12] Viskin S, Justo D, Halkin A, Zeltser D. Long QT syndrome caused by noncardiac drugs. Prog Cardiovasc Dis 2003; 45: 415-27.

[13] De Ponti F, Poluzzi E, Vaccheri A, et al. Non-antiarrhythmic drugs prolonging the QT interval: considerable use in seven countries. $\mathrm{Br}$ J Clin Pharmacol 2002; 54: 171-7.

[14] Wolbrette DL. Risk of proarrhythmia with class III antiarrhythmic agents: sex-based differences and other issues. Am J Cardiol 2003; 91 (suppl): 39D-44D.

[15] Zaręba W. Drug induced QT prolongation. Cardiol J 2007; 14: 52333.

[16] Vincent GM. The molecular genetics of the long QT syndrome: genes causing fainting and sudden death. Annu Rev Med 1998; 49: 262-74.

[17] Priori SG, Napolitano C, Schwartz PJ. Low penetrance in the long QT syndrome: clinical impact. Circulation 1999; 99: 529-33.

[18] Viskin S. Long QT syndromes and torsade de pointes. Lancet 1999; 354: 625-33.

[19] Boulet IR, Raes AL, Ottschytsch N, Snyders DJ, Roden DM. Functional effects of a KCNQ1 mutation associated with the long QT syndrome. Cardiovasc Res 2006; 70: 466-74.

[20] Schulze-Bahr E, Havercamp W, Eckardt L, Kirchhof L, Wedekind $\mathrm{H}$, Breihardt G. Genetic aspects in acquired long QT syndrome-a piece in the puzzle. Eur Heart J Suppl 2001; 3 (suppl K): K48-K52.

[21] Yang P, Kanki H, Drolet B, Yang T, Wei J, Viswanathan PC y col. Allelic variants in long-QT disease genes in patients with drugassociated torsade de pointes. Circulation 2002; 105: 1943-8.

[22 Bauman JL. The role of pharmacokinetics, drug interactions and pharmacogenetics in the acquired long QT syndrome. Eur Heart J Suppl 2001; 3 (suppl K): K93-K100.

[23] Goldstein JA. Clinical relevance of genetic polymorphisms in the human CYP2C subfamily. Br J Clin Pharmacol 2001; 52: 349-55.

[24] Mizuno N, Niwa T, Yotsumoto Y, Sugiyama Y. Impact of drug transporter studies on drug discovery and development. Pharmacol Rev 2003; 55: 425-61. 
[25] Evans WE, McLeod HL. Pharmacogenomics-drug disposition, drug targets, and side effects. N Engl J Med 2003; 348: 538-49.

[26] Mehler PS. Diagnosis and care of patients with anorexia nervosa in primary care settings. Ann Intern Med 2001; 134: 1048-59.

[27] Kay GN, Plumb VJ, Arciniegas JG, Henthorn RW, Waldo AL. Torsade de pointes: the long-short initiating sequence and other clinical features: observations in 32 patients. J Am Coll Cardiol 1983; 2: 806-17.

[28] Malik M, Farbom P, Batchhvarov V, Hnatkova K, Camm AJ. Relation between QT and RR intervals is highly individual among healthy subjects: implications for heart rate correction of the QT interval. Heart 2002; 87: 220-8.

[29] Yang T, Roden DM. Extracellular potassium modulation of drug block of Ikr: implications for torsade de pointes and reverse usedependence. Circulation 1996; 93: 407-11.

[30] Gums JG. Magnesium in cardiovascular and other disorders. Am J Health-Syst Pharm 2004; 61: 1569-76.

[31] Rieffel JA. Impact of structural heart disease on the selection of class III antiarrhythmics for the prevention of atrial fibrillation and flutter. Am Heart J 1998; 135: 551-6.

[32] Han WE, Chartier D, Li D, Nattel S. Ionic remodeling in cardiac Purkinje cells by congestive heart failure. Circulation 2001; 104: 2095-100.

[33] Nattel S, Maguy A, Le Bouter S, Yeh Y-H. Arrhythmogenic ion channel remodeling in the heart: heart failure, myocardial infarctation, and atrial fibrillation. Physiol Rev 2007; 87: 425-456.

[34] Choy AM, Lang CC, Chomsky DM, et al. Normalization of acquired QT prolongation in humans by intravenous potassium. Circulation 1997; 96: 2149-54.

[35] Marx SO, Kurokawa J, Reiken S, et al. Requirement of a macromolecular signaling complex for beta adrenergic receptor modulation of the KCNQ1-KCNE1 potassium channel. Science 2002; 295: 496-499.

[36] Nattel S, Quantz MA. Pharmacological response of quinidine induced early afterdepolarization in canine cardiac Purkinje fibres: insights into underlying ionic mechanisms. Cardiovasc Res 1988; 22: 808-17.

[37] Roden DM. Taking the "idio" out of "idiosyncratic": predicting torsades de pointes. Pacing Clin Electrophysiol 1998; 21: 1029-34.

[38] Viswanathan PC, Rudy Y. Pause induced early afterdepolarizations in the long QT syndrome: a simulation study. Cardiovasc Res 1999; 42: 530-42.

[39] Vermeulen JT, McGuire MA, Opthof T, et al. Triggered activity and automaticity in ventricular trabeculae of failing human and rabbit hearts. Cardiovasc Res 1994; 28: 1547-54.

[40] Pogwizd SM, Schlotthauer K, Li L, et al. Arrhythmogenesis and contractile dysfunction in heart failure: roles of sodium calcium exchange, inward rectifier potassium current, residual beta adrenergic responsiveness. Circ Res 2001; 88:1159-67.

[41] Pogwizd SM, Bers DM. Cellular basis of triggered arrhythmias in heart failure. Trends Cardiovasc Med 2004; 14: 61-6.

[42] Ai X, Curran JW, Shannon TR, et al. Ca2+/calmodulin-dependent protein kinase modulates cardiac ryanodine receptor phosphorylation and sarcoplasmic reticulum $\mathrm{Ca} 2+$ leak in heart failure. Circ Res 2005; 97: 1314-22.

[43] Rosenbaum MB, Blanco $\mathrm{HH}$, Elizari MV, et al. Electronic modulation of the T wave and cardiac memory. Am J Cardiol 1982; 50: 213-22.

[44] Satoh T, Zipes DP. Rapid rates during bradycardia prolong ventricular refractoriness and facilitate ventricular tachycardia induction with cesium in dogs. Circulation 1996; 94: 217-27.

[45] Shivilkin A, Danilo P, Wang J, et al. Evolution and resolution of long term cardiac memory. Circulation 1998; 97: 1810-7.

[46] Yu HG, McKinnon D, Dixon JE, et al. Transient outward current, Ito1, is altered in cardiac memory. Circulation 1999; 99: 1898-905.

[47] Libbus I, Wan X, Rosenbaum DS. Electrotonic load triggers remodeling of repolarizing current Ito in ventricle. Am J Physiol Heart Circ Physiol 2004; H1901-9.

[48] Lin JC, Quasny HA. QT prolongation and development of torsades de pointes with the concomitant administration of oral erythromycin base and quinidine. Pharmacotherapy 1997; 17: 62630.

[49] Damkier P, Hansen LL, Brosen K. Effect of diclofenac, disulfiram, itraconazole, grapefruit juice and erythromycin on the pharmacokinetics of quinidine. Br J Clin Pharmacol 1999; 48: 82938 .
[50] Gennari FJ, Hypokalemia. N Engl J Med 1998; 337: 451-8.

[51] Turgeon J, Daleau P, Bennett PB, et al. Block of IKs, the slow component of the delayed rectifier K1 current, by the diuretic agent indapamide in guinea pig myocytes. Circ Res 1994; 75: 879-86.

[52] Fiset C, Drolet B, Hamelin BA, Turgeon J. Block of IKs by the diuretic agent indapamide modulates cardiac electrophysiological effects of the class III antiarrhythmic drug dl-sotalol. J Pharmacol Exp Ther 1997; 283: 148-56.

[53] Yap YG, Camm AJ. Drug induced QT prolongation and torsades de pointes. Heart 2003; 89: 1363-72.

[54] Shantsila E, Watson T, Lip GYH. Drug-induced QT-interval prolongation and proarrhythmic risk in the treatment of atrial arrhythmias. Europace 2007; 9 (suppl. 4): iv37-44.

[55] Chiang C. Drug-induced long QT syndrome. J Med Biol Eng 2006; 26: 107-13.

[56] Pérez Riera AP, Uchida AH, Ferreira C, et al. Relationship among amiodarone, new class III antiarrhythmics, miscellaneous agents and acquired long QT syndrome. Circ J 2008; 15: 209-19.

[57] Lacy CF, Armstrong LL, Goldman MP, Lance LL. Drug Information Handbook. 17th ed. Lexi Comp, 2008. Hudson, Ohio.

[58] Maisel WH, Kuntz KM, Reimold SC, et al. Risk of initiating antiarrhythmic drug therapy for atrial fibrillation in patients admitted to a university hospital. Ann Intern Med 1997; 127: 2814.

[59] Paul AA, Witchel HJ, Hancox JC. Inhibition of HERG potassium channel current by the class 1a antiarrhythmic agent disopyramide. Biochem Biophys Res Commun 2001; 280: 1243-50.

[60] Ellenbogen KA, Wood MA, Stambler BS. Procainamide: a perspective on its value and danger. Heart Dis Stroke 1993; 2: 4736.

[61] Foo D, $\mathrm{Ng} \mathrm{KS}$. Electrocardiographical case. A case of wide complex tachycardia. Singapore Med J 2005; 46: 245-8.

[62] Grace AA, Camm AJ. Quinidine. NEJM 1998; 338: 35-45.

[63] Yang F, Hanon S, Lam P, Schweitzer P. Quinidine revisited. Am J Med 2009; 122: 317-21.

[64] Follmer CH, Colatsky TJ. Block of delayed rectifier potassium current, IK, by flecainide and E-4031 in cat ventricular myocytes. Circulation 1990; 82: 289-93.

[65] Priori SG, Napolitano C, Schwartz PJ, et al. The elusive link between LQT3 and Brugada syndrome: the role of flecainide challenge. Circulation 2000; 102: 945-7.

[66] Benito B, Brugada R, Perich RM, et al. A mutation in the sodium channel is responsible for the association of long QT syndrome and familial atrial fibrillation. Heart Rhythm 2008; 5: 1434-40.

[67] Beinart R, Michailidis A, Gurevitz OT, Glikson M. Is flecainide dangerous in long QT-3 patients? Pacing Clin Electrophysiol 2009; 32: $143-5$.

[68] Letsas KP, Efremidis M, Kounas SP, et al. Clinical characteristics of patients with drug-induced QT interval prolongation and torsade de pointes: identification of risk factors. Clin Res Cardiol 2009; 98 : 208-12.

[69] Jafari-Fesharaki M, Scheinman MM. Adverse effects of amiodarone. Pacing Clin Electrophysiol 1998; 21: 108-20.

[70] Kochiadakis GE, Igoumenidis NE, Solomou MC, et al. Conversion of atrial fibrillation to sinus rhythm using acute intravenous procainamide infusion. Cardiovasc Drugs Ther 1998; 12: 75-81.

[71] Kochiadakis GE, Igoumenidis NE, Parthenakis FI, et al. Amiodarone versus propafenone for conversion of chronic atrial fibrillation: results of a randomized, controlled study. J Am Coll Cardiol 1999; 33: 966-71.

[72] Vardas PE, Kochiadakis GE, Igoumenidis NE, et al. Amiodarone as a first-choice drug for restoring sinus rhythm in patients with atrial fibrillation: A randomized, controlled study [in Process Citation]. Chest 2000; 117: 1538-45.

[73] Sung RJ, Tan HL, Karagounis L, et al. Intravenous sotalol for the termination of supraventricular tachycardia and atrial fibrillation and flutter: a multicenter, randomized, double-blind, placebocontrolled study. Sotalol Multicenter Study Group. Am Heart J 1995; 129: 739-48.

[74] Vos MA, Golitsyn SR, Stangl K, et al. Superiority of ibutilide (a new class III agent) over DL-sotalol in converting atrial flutter and atrial fibrillation. The Ibutilide/Sotalol Comparator Study Group. Heart 1998; 79: 568-75.

[75] Reisinger J, Gatterer E, Heinze G, et al. Prospective comparison of flecainide versus sotalol for immediate cardioversion of atrial fibrillation. Am J Cardiol 1998; 81: 1450-4. 
[76] Chung MK, Schweikert RA, Wilkoff BL, et al. Is hospital admission for initiation of antiarrhythmic therapy with sotalol for atrial arrhythmias required? Yield of in-hospital monitoring and prediction of risk for significant arrhythmia complications. J Am Coll Cardiol 1998; 32: 169-76.

[77] Kiehn J, Lacerda AE, Wible B, Brown AM. Molecular physiology and pharmacology of HERG. Single-channel currents and block by dofetilide. Circulation 1996; 94: 2572-9.

[78] Pedersen HS, Elming H, Seibaek M, et al. DIAMOND Study Group. Risk factors and predictors of Torsade de pointes ventricular tachycardia in patients with left ventricular systolic dysfunction receiving Dofetilide. Am J Cardiol 2007; 100: 876-80.

[79] Aström-Lilja C, Odeberg JM, Ekman E, Hägg S. Drug-induced torsades de pointes: a review of the Swedish pharmacovigilance database. Pharmacoepidemiol Drug Saf 2008; 17: 587-92.

[80] Srivastava A, Khan MA, Watkiss J. Post induction arrhythmia in a renal patient: an unexpected risk factor. Anaesthesia 2009; 64: 43943.

[81] Yalta K, Turgut O, Yilmaz A, et al. Torsades de pointes with a severely prolonged QT interval induced by an initial low dose sotalol intake. Int J Cardiol 2007; 116: e95-7.

[82] Letsas KP, Efremidis M, Sideris M. Sotalol unmasks susceptibility to drug-induced long QT syndrome and torsades de pointes. Int J Cardiol 2008; 124: 366-7.

[83] Cherpanath TG, Geisler FE, van der Meer BJ, van Veer NE, Alings AM. Suicide attempt with sotalol: a proarrhythmic intoxication. Ned Tijdschr Geneeskd. 2007; 151: 2214-8.

[84] Linz DK, Afkham F, Itter G, Rütten H, Wirth KJ. Effect of atrial electrical remodeling on the efficacy of antiarrhythmic drugs: comparison of amiodarone with $\mathrm{I}(\mathrm{Kr})$ - and I(to)/IKur-blockade in vivo. J Cardiovasc Electrophysiol 2007; 18: 1313-20.

[85] Ravina T, Ravina P, Gutierrez J. Acquired long QT syndrome: Unequal regression of Amiodarone induced repolarization lengthening. Int J Cardiol 2008; 124: 395-9.

[86] Imai S, Saito F, Takase H, et al. Use of bepridil in combination with Ic antiarrhythmic agent in converting persistent atrial fibrillation to sinus rhythm. Circ J 2008; 72: 709-15.

[87] Fujiki A, Tsuneda T, Sugao M, Mizumaki K, Inoue H. Usefulness and safety of bepridil in converting persistent atrial fibrillation to sinus rhythm. Am J Cardiol 2003; 92: 472-5.

[88] Nakazato Y, Yasuda M, Sasaki A, et al. Conversion and maintenance of sinus rhythm by bepridil in patients with persistent atrial fibrillation. Circ J 2005; 69: 44-8.

[89] Miyaji K, Tada H, Fukushima KK, et al. Efficacy and safety of the additional bepridil treatment in patients with atrial fibrillation refractory to class I antiarrhythmic drugs. Circ J 2007; 71: 1250-7.

[90] Prystowsky EN. Effects of bepridil on cardiac electrophysiologic properties. Am J Cardiol 1992; 69: 63D-7D.
[91] Yasuda M, Nakazato Y, Sasaki A, et al. Clinical evaluation of adverse effects during bepridil administration for atrial fibrillation and flutter. Circ J 2006; 70: 662-6.

[92] Wang CP, Guo GB. Indapamide induced syncope in a patient with long QT syndrome. Pacing Clin Electrophysiol 2002; 25: 1397-9.

[93] Lu Y, Yue L, Wang Z, Nattel S. Effects of the diuretic agent indapamide on $\mathrm{Na}+$, transient outward, and delayed rectifier currents in canine atrial myocytes. Circ Res 1998; 83: 158-66.

[94] Letsas KP, Alexanian IP, Pappas LK, et al. Letter to the Editor. QT interval prolongation and torsade de pointes associated with indapamide. Int J Cardiol 2006; 112: 373-4.

[95] Kijtawornrat A, Hamlin RL, Hamlin DM. Effects of ambasilide in isolated perfused guinea pig heart: use dependence. Cardiovasc Toxicol 2005; 5: 53-62.

[96] Sager PT, Nademanee K, Antimisiaris M, et al. Antiarrhythmic effects of selective prolongation of refractoriness. Electrophysiologic actions of sematilide $\mathrm{HCl}$ in humans. Circulation 1993; 88: 1072-82.

[97] Wong W, Pavlou HN, Birgersdotter UM, et al. Pharmacology of the class III antiarrhythmic agent sematilide in patients with arrhythmias. Am J Cardiol 1992; 69: 206-12.

[98] SoRelle R. Withdrawal of Posicor from market [news]. Circulation 1998; 98: 831-2.

[99] Levine TB, Bernink PJ, Caspi A, et al. Effect of mibefradil, a Ttype calcium channel blocker, on morbidity and mortality in moderate to severe congestive heart failure: the MACH-1 study. Mortality Assessment in Congestive Heart Failure Trial. Circulation 2000; 101: 758-64

[100] Miyajima K, Minatoguchi S, Ito Y, et al. Reduction of QTc dispersion by the angiotensin II receptor blocker valsartan may be related to its anti-oxidative stress effect in patients with essential hypertension. Hypertens Res 2007; 30: 307-13.

[101] Abraham J, Mudd JO, Kapur N, Klein K, Champion HC, Wittstein IS. Stress cardiomyopathy after intravenous administration of catecholamines and beta-receptor agonists. J Am Coll Cardiol 2009; 53: 1320-5.

[102] Quan F, Peng G, Kangan C, Dayi H, Cuilan L, Richard CC. Dobutamine Infusion for Unmasking Long QT Syndrome and Torsades de Pointes. Clin Cardiol 2009, in press. 7 april (Epub ahead of print).

[103] Peitz GJ, Malesker MA, Sojka SG. Aliskiren-induced QT interval prolongation. South Med J 2009; 102: 411-2.

[104] Vincent GM, Schwartz PJ, Denjoy I, et al. High efficacy of betablockers in long-QT syndrome type 1: contribution of noncompliance and QT-prolonging drugs to the occurrence of betablocker treatment "failures". Circulation 2009; 119: 215-21.

[105] Erdil F, Demirbilek S, Begec Z, et al. The effect of esmolol on the QTc interval during induction of anaesthesia in patients with coronary artery disease. Anaesthesia 2009; 64: 246-50. 